\title{
Precautionary Savings or Working Longer Hours?*
}

\author{
Josep Pijoan-Mas \\ CEMFI and CEPR
}

November 2005

\begin{abstract}
This paper quantifies the macroeconomic implications of the lack of insurance against idiosyncratic labor market risk. I show that in a model economy calibrated to observed individual level data, households make ample use of work effort as a consumption smoothing mechanism. As a consequence, aggregate consumption is $0.6 \%$ lower, work effort is $18 \%$ higher and labor productivity is $12 \%$ lower than they would be in a complete markets setting. Not surprisingly, the welfare benefits of moving towards complete markets are very large. Accounting for the whole transition to the new complete markets steady state I find the welfare costs of market incompleteness above $16 \%$ of individual lifetime consumption.
\end{abstract}

Keywords: Incomplete Markets; Labor Supply; Precautionary Savings

JEL Classification: E21; D31; J22; C68

*The author thanks comments by Richard Blundell, Marco Cozzi, Javier Díaz-Giménez, David Domeij, Ana Fernandes, Martin Flodén, Jonathan Heathcote, Mark Huggett, Albert Marcet, Víctor Ríos-Rull, Kjetil Storesletten, Gustavo Ventura, Gianluca Violante and attendants to the 2005 World Congress of the Econometric Society, London, 2004 Society for Economic Dynamics Annual Meeting, Florence, the 2003 Workshop on Dynamic Macroeconomics, Vigo, the 2003 Summer Meeting of Economic Analysis, Vigo and seminars at CEMFI, the Federal Reseve Bank of Atlanta, Georgetown University, Penn State University, Stockholm School of Economics and University College London. The paper has also benefited from suggestions by two anonymous referees. All remaining errors are my own. E-mail address: pijoan@cemfi.es 


\section{Introduction}

Empirical evidence reveals a very low cross-sectional correlation between hours of work and wages. If individuals perceive wage differences to be permanent, then the lack of correlation between hours and wages just tells us that preferences are such that the substitution and the income effect compensate each other. However, several studies show that a big fraction of the cross-sectional dispersion in wages is due to non-permanent stochastic factors. ${ }^{1}$ According to this, even if the income and substitution effects compensate each other, we would expect individuals to take advantage of better labor market opportunities and work more when more productive and enjoy leisure when less. This substitution of work effort across periods is limited by two different factors. First, the available financial technology to transfer resources from high wage to low wage periods, and second, individual preferences for both smooth consumption and smooth leisure. In particular, if there existed assets whose payment was contingent on the wage perceived by individuals, then the substitution of work effort across periods would depend only on individuals preferences.

The purpose of this paper is to assess quantitatively the macroeconomic implications of the lack of markets to insure against idiosyncratic labor market risk. I use a standard dynamic general equilibrium model with heterogenous agents where households take consumption/saving and labor/leisure decisions. Key parameters as the intertemporal elasticities of substitution for consumption and leisure are inferred from household level data. Then, I quantify the effects of market incompleteness on the aggregate amount of hours worked, labor productivity, aggregate capital, aggregate output, aggregate consumption and individual welfare.

I find that the quantitative effects of market incompleteness are very big. For an economy calibrated to both aggregate and individual level data from the US, the lack of a financial technology to insure against labor market risk changes dramatically the labor supply of households. Within the model, the lack of cross-sectional correlation between hours and wages is interpreted as households using labor supply as a mechanism to keep a smooth pattern of consumption. This is reflected in the labor productivity. In the calibrated incomplete markets economy, labor productivity is $19.3 \%$ lower than in the complete markets economy when holding capital fixed and $11.5 \%$ lower when allowing capital to adjust. In addition, work effort is

\footnotetext{
${ }^{1}$ For instance, Card (1991), Flodén and Lindé (2001), French (2003) or Heathcote, Storesletten, and Violante (2004).
} 
much higher in the incomplete markets economy: the lack of state contingent bonds is responsible for $18 \%$ of the observed work effort.

The reason for these results is as follows. Under complete markets, households substitute leisure across different states, working long hours when their market productivity is high and working few or none hours when their market productivity is low. State contingent assets allow consumers to transfer resources between states and keep the marginal utility of consumption equal across states. In contrast, in the incomplete markets world households are not so willing to substitute labor across states precisely because the ability to transfer resources between states is limited. In the steady state equilibrium, a large fraction of low productivity workers are also asset-poor. This type of households will supply many hours in spite of not being very productive because their marginal utility of consumption is very high. At the same time a large fraction of high productivity workers are asset-rich. This type of households will not supply many hours of work because their marginal utility of consumption is very low. Ultimately, the total amount of labor measured in efficiency units is low, the work effort high and the labor productivity low.

Notice therefore that the mechanics driving the quantitative results of the paper is that households make ample use of their labor supply as a self-insurance mechanism in absence of state contingent assets. Do they rely more in precautionary savings or in working long hours? For the benchmark economy I find that precautionary savings are equal to $18.6 \%$ of aggregate capital whereas the share of hours worked in the incomplete markets economy in excess of the amount of hours worked in the complete markets economy is $15.2 \%$. With a somewhat more persistent wage process these figures become $3.7 \%$ and $20.7 \%$. Therefore, a salient quantitative result of this paper is that households seem to be using their work effort as a self-insurance mechanism at least as much as they do with savings if not more, the exact measurement depending on the persistence of the non-deterministic component of the wage process. This is consistent with empirical evidence. For instance, Parker, Belghitar, and Barmby (2005), using data from self-employed individuals in the PSID, find increases in hours of work as a response to increases in uncertainty.

Last, but not least, the welfare benefits associated to the introduction of markets to insure against idiosyncratic risk are huge and vary substantially among households. The average over the whole population of the percentage increase in lifetime consumption required by a household to be indifferent between the incomplete and the complete markets economy is $16 \%$. When explicitly accounting for the transi- 
tion, this figure rises to $16.5 \%$. The reason is that the transition is quite a pleasant affair because it allows households to eat their precautionary savings. The literature on market completeness so far has emphasized the welfare benefits of eliminating fluctuations in consumption. ${ }^{2}$ The welfare gains due to the increased labor productivity have been somehow overlooked. I find that labor productivity contributes more than $40 \%$ to the welfare increase. In a very recent and complementary work, Heathcote, Storesletten, and Violante (2005) also find that the increase in labor productivity accounts for a big share of the welfare benefits associated to complete markets.

There is relatively little work on the interaction of savings and work effort as selfinsurance mechanisms. In a two period model, Flodén (2005) shows theoretically the importance of the joint determination of labor supply and savings when future wages are uncertain. In a different type of work, Low (2005) examines the life-cycle consumption and labor allocations in a partial equilibrium context and finds that for a given set of parameters, a model with endogenous labor supply generates higher savings than an exogenous labor model. However, he does not directly measure precautionary savings. Finally, in a general equilibrium model Marcet, Obiols-Homs, and Weil (2003) argue that with the explicit consideration of endogenous labor supply we may find negative precautionary savings. However, contrary to the results presented here, in their model this goes necessarily through a lower amount of hours worked in the incomplete markets economy. This is an important difference and I will come back to it.

The reminder of the paper is organized as follows. Section 2 describes the theoretical set up. Section 3 explains how the model economy is calibrated to data. Then, the model economy is simulated in and the results presented and discussed in section 4 . Section 5 performs some robustness checks of the results. Finally, section 6 concludes.

\section{The model economies}

The economies analyzed in this paper are growth economies with production, populated by a measure one of households that live forever. In this section I will only look at steady states.

\footnotetext{
${ }^{2}$ See for example Kubler and Schmedders (2001).
} 


\subsection{Preferences}

Households derive utility from consumption and leisure. Current consumption is denoted by $c$ and leisure by $l$. Future utilities are discounted at the rate $\beta \in(0,1)$. I write the per period utility as $u(c, l)$, and total expected utility at time $\tau$ as $E_{\tau} \sum_{t=\tau}^{\infty} \beta^{t-\tau} u\left(c_{t}, l_{t}\right)$.

\section{$2.2 \quad$ Production technology}

Each period households receive a shock to their efficiency units of labor $\varepsilon \in \Upsilon \equiv$ $\left\{\varepsilon_{1}, \ldots, \varepsilon_{n_{\varepsilon}}\right\}$. This shock is Markov with transition matrix $\Gamma$, with $\Gamma_{\varepsilon \varepsilon^{\prime}}$ stating $\operatorname{Pr}\left(\varepsilon_{t+1}=\varepsilon^{\prime} \mid \varepsilon_{t}=\varepsilon\right)$.

Aggregate output $Y$ is produced according to an aggregate neoclassical production function $F(K, L)$ that takes as inputs capital $K$ and efficient units of labor $L$. The aggregate labor input comes from aggregating over all agents' efficiency units of labor worked. Aggregate capital results from aggregation of all assets. Capital depreciates at an exogenous rate $\delta \in(0,1)$.

\subsection{Market arrangements}

I distinguish between two types of market arrangements. The benchmark economy is an incomplete markets economy. By incomplete markets I mean that there are no state contingent markets for the household specific shock $\varepsilon$. Households hold assets $a \in[\underline{a}, \infty)$ that pay interest at rate $r$. I assume that households are restricted by a lower bound on their assets holdings $\underline{a}^{3}$

In the complete markets economy households can trade Arrow securities contingent on the realization of their own idiosyncratic shock. I denote by $b^{\prime}\left(\varepsilon^{\prime}\right)$ the amount of units of the consumption good to be paid to the security holder at the beginning of next period if next period idiosyncratic shock is $\varepsilon^{\prime}$. I denote by $q\left(\varepsilon, \varepsilon^{\prime}\right)$ the price that a household of type $\varepsilon$ has to pay in the current period for such a security. A way to decentralize the economy with complete markets is by assuming there is an insurance sector with free entry that operates a costless monitoring technology such that the realizations of the efficiency units endowments are perfectly observable.

\footnotetext{
${ }^{3}$ This lower bound may arise endogenously as the quantity that ensures that the household is capable of repaying its debt in all states of the world or we can just set it exogenously as a borrowing constraint. See Huggett (1993) and Aiyagari (1994) for details.
} 


\subsection{Incomplete markets economies}

The individual state variables are the shock realization $\varepsilon$ and the stock of assets $a .^{4}$ The problem that the household solves is:

$$
\begin{array}{cl} 
& v(\varepsilon, a)=\max _{c, l, a^{\prime}}\left\{u(c, l)+\beta \sum_{\varepsilon^{\prime}} \Gamma_{\varepsilon \varepsilon^{\prime}} v\left(\varepsilon^{\prime}, a^{\prime}\right)\right\} \\
\text { s.t.: } \quad & c+a^{\prime}=w \varepsilon(1-l)+(1+r) a \\
& c \geq 0, \quad 1 \geq l \geq 0 \quad \text { and } \quad a^{\prime} \geq \underline{a}
\end{array}
$$

where $r$ and $w$ are the return on assets and the rental rate per efficiency units of labor. Under certain conditions problems of this type have a solution that we denote $a^{\prime}=g^{a}(\varepsilon, a), c=g^{c}(\varepsilon, a)$ and $l=g^{l}(\varepsilon, a)$ with an upper bound on asset holdings, $\bar{a}$ such that $\bar{a} \geq g^{a}(\varepsilon, a) \geq \underline{a}$ for all $\varepsilon \in \Upsilon$ and all $a \in A \equiv[\underline{a}, \bar{a}]{ }^{5}$ Hereafter I will also use the more compact notation $s \equiv\{\varepsilon, a\}$ and $S \equiv \Upsilon \times A$.

It is possible to construct a Markov process for the individual state variables, from the Markov process on the shocks and from the decision rules of the agents. ${ }^{6}$ Let $\mathcal{B}$ be the $\sigma$-algebra generated in $S$ by, say, its open intervals. A probability measure $\mu$ over $\mathcal{B}$ exhaustively describes the economy by stating how many households are of each type. Let $Q(s, B)$ denote the probability that a type $s=\{\varepsilon, a\}$ has of becoming of a type in $B \subset \mathcal{B}$. Given the objects defined so far, we can express $Q$ as:

$$
Q(s, B)=\sum_{\varepsilon^{\prime} \in B_{\varepsilon}} \Gamma_{\varepsilon \varepsilon^{\prime}} \mathbf{I}_{g(\varepsilon, a) \in B_{a}}
$$

where $\mathbf{I}$ is an indicator function that takes value 1 if its argument is true and 0 otherwise, $B_{\varepsilon}$ is the projection of $B$ in $\Upsilon$ and $B_{a}$ is the projection of $\mathrm{B}$ in $A$. The transition function $Q$ describes the evolution of the economy by generating a probability measure for next period $\mu^{\prime}$ given a probability measure $\mu$ today. The exact way in which this occurs is

$$
\mu^{\prime}(B)=\int_{S} Q(s, B) d \mu
$$

Definition $1 A$ steady state equilibrium for the incomplete markets economy is a set of functions $\left\{v, g^{a}, g^{c}, g^{l}\right\}$, a measure of households $\mu$, and a pair of prices

\footnotetext{
${ }^{4}$ Since there is no aggregate uncertainty and since we only look at steady states, there are no aggregate state variables.

${ }^{5}$ See Huggett (1993) and Marcet, Obiols-Homs, and Weil (2003) for details.

${ }^{6}$ See Huggett (1993) or Hopenhayn and Prescott (1992) for details.
} 
$\{w, r\}$ such that: (1) given a pair of prices $\{w, r\}$, the functions $\left\{v, g^{a}, g^{c}, g^{l}\right\}$ solve the households' decision problem; (2) prices are given by marginal productivities, $r=F_{K}(K / L)-\delta$ and $w=F_{L}(K / L)$; (3) factor inputs are obtained aggregating over households, $L=\int \varepsilon\left(1-g^{l}\right) d \mu$ and $K=\int g^{a} d \mu$; (4) the measure of households is stationary, $\mu(B)=\int_{S} Q(s, B) d \mu$ and (5) by virtue of the Walras law, the aggregate resource constraint of the economy is automatically satisfied, $C+K^{\prime}=F(K, L)+$ $(1-\delta) K$.

\subsection{Complete markets economies}

Under complete markets, the individual level state variables are the realization of the idiosyncratic shock $\varepsilon$ and the income obtained from the corresponding Arrow security $b(\varepsilon)$. The problem that the household solves is:

$$
\begin{array}{ll}
v(\varepsilon, b(\varepsilon))= & \max _{c, l, b^{\prime}\left(\varepsilon^{\prime}\right)}\left\{u(c, l)+\beta \sum_{\varepsilon^{\prime}} \Gamma_{\varepsilon \varepsilon^{\prime}} v\left(\varepsilon^{\prime}, b^{\prime}\left(\varepsilon^{\prime}\right)\right)\right\} \\
\text { s.t.: } & c+\sum_{\varepsilon^{\prime}} q\left(\varepsilon, \varepsilon^{\prime}\right) b^{\prime}\left(\varepsilon^{\prime}\right)=w \varepsilon(1-l)+b(\varepsilon) \\
& c \geq 0 \text { and } 1 \geq l \geq 0
\end{array}
$$

The solution to this problem is given by the policy functions $b^{\prime}\left(\varepsilon^{\prime}\right)=g^{b}\left(\varepsilon, b(\varepsilon), \varepsilon^{\prime}\right)$, $c=g^{c}(\varepsilon, b)$ and $l=g^{l}(\varepsilon, b)$.

For a household of type $\{\varepsilon, b(\varepsilon)\}$ we have an Euler equation for each state contingent bond $b^{\prime}\left(\varepsilon^{\prime}\right)$ :

$$
u_{c}(c, l)=\beta \frac{\Gamma_{\varepsilon \varepsilon^{\prime}}}{q\left(\varepsilon, \varepsilon^{\prime}\right)} u_{c}\left(c^{\prime}, l^{\prime}\right) \quad \forall \varepsilon^{\prime} \in \Upsilon
$$

where $l$ is given by the intratemporal first order condition:

$$
u_{c}(c, l) w \varepsilon=u_{l}(c, l)
$$

Imposing equilibrium in the insurance market $q\left(\varepsilon, \varepsilon^{\prime}\right)=(1+r)^{-1} \Gamma_{\varepsilon \varepsilon^{\prime}}$ the Euler equations can be rewritten as:

$$
u_{c}(c, l)=\beta(1+r) u_{c}\left(c^{\prime}, l^{\prime}\right) \quad \forall \varepsilon^{\prime} \in \Upsilon
$$

which tells us that households will choose their purchases of state contingent bonds such that the next period marginal utilities of consumption are equalized across 
states. $^{7}$ Therefore, for a steady state equilibrium with a balanced growth path to exist we will require $\beta(1+r)=1 .^{8}$ This condition further simplifies the Euler equations for the state contingent bonds:

$$
u_{c}(c, l)=u_{c}\left(c^{\prime}, l^{\prime}\right) \quad \forall \varepsilon^{\prime} \in \Upsilon
$$

This is the standard complete markets relationship. Households choose $b^{\prime}\left(\varepsilon^{\prime}\right)$ such that the marginal utility of consumption is equalized across different states of the world and different points in time.

Definition $2 A$ steady state equilibrium for the complete markets economy is a set of functions $\left\{v, g^{b}, g^{c}, g^{l}\right\}$, a measure of households $\mu$, a pair of prices $\{w, r\}$ and a pricing function $q\left(\varepsilon, \varepsilon^{\prime}\right)$ such that: (1) given a pair of prices $\{w, r\}$ and the pricing function $q\left(\varepsilon, \varepsilon^{\prime}\right)$, the functions $\left\{v, g^{b}, g^{c}, g^{l}\right\}$ solve the households' decision problem; (2) prices are given by marginal productivities, $r=F_{K}(K / L)-\delta$ and $w=F_{L}(K / L)$; (3) factor inputs are obtained aggregating over households, $L=\int \varepsilon\left(1-g^{l}\right) d \mu$ and $K=\int \sum_{\varepsilon^{\prime}} q\left(\varepsilon, \varepsilon^{\prime}\right) g^{b}\left(\varepsilon, b(\varepsilon), \varepsilon^{\prime}\right) d \mu$; (4) the pricing function $q\left(\varepsilon, \varepsilon^{\prime}\right)$ satisfies the no-arbitrage condition in the insurance industry, $q\left(\varepsilon, \varepsilon^{\prime}\right)=(1+r)^{-1} \Gamma_{\varepsilon \varepsilon^{\prime}} ;$ (5) the steady state condition $\beta(1+r)=1$ holds; and (6) by virtue of the Walras law, the aggregate resource constraint of the economy is automatically satisfied, $C+K^{\prime}=$ $F(K, L)+(1-\delta) K$.

Unlike the incomplete market economy, the steady state equilibrium is not unique. There is a unique set of prices $r, w$ and $q\left(\varepsilon, \varepsilon^{\prime}\right)$ and capital labor ratio $K / L$ pinned down by the equilibrium conditions (2), (4) and (5). Given a unique set of prices, condition (1) implies a unique set of functions $\left\{v, g^{b}, g^{c}, g^{l}\right\}$ and therefore the optimal individual behavior is also uniquely determined. However, for general types of preferences, condition (3) implies that different distributions of households $\mu$ generate different pairs of aggregate capital $K$ and aggregate labor $L$ consistent with the unique capital to labor ratio. ${ }^{9}$ Indeed, there are potentially infinite differ-

${ }^{7}$ Or the consumption level itself if consumption and leisure are separable in the utility function.

${ }^{8}$ Notice that if $\beta(1+r)>1$ we would need

$$
u_{c}(c, l)>u_{c}\left(c^{\prime}, l^{\prime}\right) \quad \forall \varepsilon^{\prime} \in \Upsilon
$$

which asks for consumption (and therefore assets) to grow forever. If $\beta(1+r)<1$ the opposite would be true.

${ }^{9}$ In particular, with valued leisure and heterogeneous and time-changing endowments of labor productivity, Gorman (1953) aggregation result does not hold: homotheticity of preferences is not a sufficient condition for aggreation. See Maliar and Maliar (2003) for details. 
ent distributions $\mu$ compatible with the unique equilibrium capital to labor ratio. ${ }^{10}$ These different distributions will generate different levels of aggregate capital and labor and therefore of hours worked, output and aggregate consumption. Therefore, contrary to an economy without valued leisure, we cannot characterize the solution to the complete markets economy by use of a representative agent. When solving for the complete markets economy we need to make explicit which equilibrium we choose.

\section{Calibration}

The length of the model period is set equal to one year. The calibration strategy I pursue is the following. Given an exogenous process for the efficiency endowment $\varepsilon$, I choose the model parameters such that in the steady state equilibrium the incomplete markets economy matches some characteristics of both aggregate and individual level data. This implies solving for the equilibrium as many times as needed until the statistics from data are matched. ${ }^{11}$ In a sense, this calibration strategy can be seen as an exactly identified simulated method of moments estimation. Then, given these parameters the complete markets economies are solved. In the remaining of this section I give more details about this process.

\subsection{The process for individual wages}

The process for market productivity shocks $\varepsilon$ is determined by an $n_{\varepsilon} \times 1$ vector of endowments $\Upsilon$ and an $n_{\varepsilon} \times n_{\varepsilon}$ transition matrix $\Gamma$. The first step for the calibration is to give values to the parameters of this process by looking at data on wages.

The model is set such that there is no fixed heterogeneity. In this model economy all households will be at some point at the top and at some other point at the bottom of the wage distribution. If we mapped the actual distribution of wages into the model, we would be imposing for instance that a computer engineer may end up being as productive as an assembly line worker (and viceversa). The large variance of earnings observed in data does not seem to reflect actual uncertainty

\footnotetext{
${ }^{10}$ The lack of uniqueness is broken by the fact that the steady state condition $\beta R=1$ implies that in equilibrium individual assets may lay at any point in the unbounded set $[\underline{a}, \infty)$ and therefore the state space described by the set $S$ is not compact. Therefore, theorem 2 in Hopenhayn and Prescott (1992) does not hold.

${ }^{11}$ Other recent articles that follow a similar calibration strategy in a similar context are Castañeda, Díaz-Giménez, and Ríos-Rull (2003) and Heathcote, Storesletten, and Violante (2004).
} 
faced by people. Therefore, instead of calibrating the model productivity process to the overall dispersion of the observed wage distribution I will take as reference the wage distribution net of fixed heterogeneity.

There are several articles estimating processes for wages. Let's call $\omega_{i, t}$ the log of the real hourly wage at $t$ earned by individual $i$. A typical set up is as follows:

$$
\omega_{i, t}=\gamma x_{i, t}+\alpha_{i}+z_{i, t}+v_{i, t} \quad \text { with } v_{i, t} \sim N\left(0, \sigma_{v}^{2}\right)
$$

where $x_{i, t}$ is a vector of observable characteristics, $\alpha_{i}$ reflects an individual $i$ unobserved fixed component, $v_{i, t}$ may reflect measurement error and $z_{i, t}$ is an stochastic time changing individual specific component that evolves as follows:

$$
z_{i, t}=\rho z_{i, t-1}+\eta_{i, t} \quad \text { with } \eta_{i, t} \sim N\left(0, \sigma_{\eta}^{2}\right)
$$

This idiosyncratic component $z$ is the one that corresponds to the (log of the) model productivity term $\varepsilon$.

Estimates of this idiosyncratic component vary. Using PSID data, Flodén and Lindé (2001) estimate $\rho=0.92$ and $\sigma_{\eta}=0.21$. Also using PSID data French (2003) finds a somewhat more persistent process with $\rho=0.977$ and $\sigma_{\eta}=0.12$. French estimate implies also a slightly more volatile idiosyncratic component for wages, with $\sigma_{z}=0.56$, whereas Flodén and Lindé parameters imply $\sigma_{z}=0.54{ }^{12}$

I will parameterize the process for $\varepsilon$ by discretizing each of these two estimations into a seven-state markov chain following the methodology described by Tauchen (1986). I will call $E_{0}$ the economy that arises from the discretization of the process estimated by Flodén and Lindé (2001). In section 5.3, I will also provide results for the economy that arises from the discretization of the more persistent process estimated by French (2003).

\subsection{The calibration in equilibrium}

The production function is the standard Cobb-Douglas, which is consistent with the non-trended factor shares observed in US data for the post-war years:

$$
F(K, L)=K^{1-\theta} L^{\theta}
$$

\footnotetext{
${ }^{12}$ These are not the only studies estimating a process for the idiosyncratic and stochastic component of wages by use of PSID data. Earlier work by Card (1991) provides a less persistent process with $\rho=0.89$. Heathcote, Storesletten, and Violante (2004) obtain $\rho=0.94$.
} 
The chosen utility function is:

$$
u(c, l)=\frac{c^{1-\sigma}-1}{1-\sigma}+\lambda \frac{l^{1-\nu}-1}{1-\nu}
$$

It gives enough parameters to have distinct intertemporal elasticities of substitution for consumption and leisure which let us match observed individual behavior. ${ }^{13}$ With this utility function, the intertemporal elasticity of substitution of consumption is given by $\frac{1}{\sigma}$, the intertemporal elasticity of substitution of leisure by $\frac{1}{\nu}$ and the intertemporal elasticity of substitution of labor by $\frac{l}{\nu(1-l)}$.

There are 6 parameters we want to pin down: the preference parameters $\beta, \sigma$, $\nu, \lambda$ and the technology parameters $\theta$ and $\delta .{ }^{14}$ I will calibrate these values so that in equilibrium the incomplete markets economy matches some statistics from data, taking three targets from aggregate data and three targets from household survey data.

Table 1: Calibration targets and model parameters.

\begin{tabular}{ccc}
\hline \hline parameter & target & value \\
\hline$\sigma$ & $\operatorname{cor}(h, \varepsilon)=0.02$ & 1.458 \\
$\nu$ & $c v(h)=0.22$ & 2.833 \\
$\lambda$ & $H=0.33$ & 0.856 \\
$\beta$ & $K / Y=3.00$ & 0.945 \\
$\theta$ & $w L / Y=0.64$ & 0.640 \\
$\delta$ & $I / Y=0.25$ & 0.083 \\
\hline \hline
\end{tabular}

The three targets from aggregate data are quite standard choices. I will use the capital to output ratio, the ratio of investment to output and the labor share. These statistics should mainly pin down the time discount factor $\beta$, the depreciation rate $\delta$ and the labor share parameter $\theta$. I pick a value of 3.0 for the capital labor ratio, a value of 0.25 for the investment output ratio and a labor share of 0.64 . They are all fairly common choices for general equilibrium model economies.

I use the Current Population Survey (CPS) for 2002 to compute the three targets from cross-sectional household survey data as follows. ${ }^{15}$ First, I choose the average

\footnotetext{
${ }^{13}$ Notice however that $\sigma \neq 1$ is inconsistent with balanced growth path in a representative agent economy with positive growth.

${ }^{14}$ The lower level on asset holdings $\underline{a}$ is set equal to the natural borrowing limit. Since in this model there are no transfers and labor income depends on hours supplied the natural borrowing limit turns out to be zero. Less stringent borrowing limits are explored in section 5.1.

${ }^{15}$ I actually use the 2002 NBER Merged Outgoing Rotation Groups sub-sample of the CPS data set, which contains the 4 th and 8 th month interviews of every household.
} 
number of hours worked in the sample which is roughly $1 / 3$ of available time. Second, I use the cross-sectional correlation of wages with hours. Third, I target the crosssectional volatility of hours worked. These three statistics will pin down the three parameters of the utility function. In doing so I follow Heathcote, Storesletten, and Violante (2004). ${ }^{16}$ To accord with the model lack of deterministic heterogeneity, I clean hours and wages from fixed heterogeneity. I regress out education, age, sex and race from wages and hours and compute (a) the correlation of the residual of hours with the residual of wages and (2) the coefficient of variation of the residual of hours. The correlation turns out to be a very small $0.02 .{ }^{17}$ The coefficient of variation of hours is 0.22 .

Table 1 contains the parameter values consistent with a steady state equilibrium displaying these six properties from data. ${ }^{18}$ We obtain $\sigma=1.458$ and $\nu=2.833$. The former value implies an intertemporal elasticity of substitution for consumption of 0.69 , a value in line with many macroeconomic papers. The latter value implies an intertemporal elasticity of substitution for leisure equal to 0.35 and for labor equal to 0.72 (when evaluated at its average). Empirical estimates of the intertemporal elasticity of labor using micro data on male household heads tend to be lower than this number. However, according to Domeij and Flodén (2003) estimates that do not take into account borrowing constraints may be seriously downward biased. These authors, when controlling for borrowing constraints, estimate an elasticity of labor around $0.59 .^{19}$

As an assessment of this model economy, in table 2 I display some distributional statistics and compare them to data. In the first panel I report the statistics for hours. The coefficient of variation of hours has been calibrated so the model and data coincide. The rest of the distribution has not. We see that the model generates an average amount of hours worked at each quintile of the distribution of hours very

\footnotetext{
${ }^{16}$ However, these authors target the volatility of the change in hours instead of the volatility of levels. Both choices gives a measure of the size of fluctuations in leisure that households face. The choice of targeting the change in hours is not available with the CPS. When looking for a source of labor market data one faces a trade-off between the PSID and the CPS. The former is a long panel but the latter is much larger and its sampling constantly redesigned in order to be representative of the US population.

${ }^{17}$ Heathcote, Storesletten, and Violante (2004) also report a value of 0.02 for the period 19671996 using PSID data.

${ }^{18}$ Notice that since the parameters are calibrated to equilibrium statistics, all of them affect all calibration targets. However, in the text I highlight the statistic that is most influenced by each parameter.

${ }^{19}$ In section 5.1 I show that when allowing households to hold negative net worth, the calibrated elasticity of labor reaches 0.59 . See section 5.2 for a further discussion on this issue and robustness checks for $\nu$.
} 
Table 2: Distributional statistics.

\begin{tabular}{lccccccc}
\hline \hline variable & $c v$ & gini & $q_{1}$ & $q_{2}$ & $q_{3}$ & $q_{4}$ & $q_{5}$ \\
\hline $\begin{array}{l}\text { hours } \\
\quad \text { model } E_{0}\end{array}$ & 0.22 & 0.11 & 0.21 & 0.31 & 0.35 & 0.37 & 0.40 \\
$\quad$ data (CPS) & 0.22 & 0.11 & 0.24 & 0.31 & 0.33 & 0.35 & 0.42 \\
\hline earnings & & & & & & & \\
$\quad$ model $E_{0}$ & 0.65 & 0.33 & $7.3 \%$ & $12.4 \%$ & $17.2 \%$ & $23.0 \%$ & $40.1 \%$ \\
$\quad$ data $(\mathrm{CPS})$ & 0.56 & 0.29 & $7.9 \%$ & $13.7 \%$ & $18.0 \%$ & $23.3 \%$ & $37.1 \%$ \\
$\quad$ data (SCF) & 2.65 & 0.61 & $-0.2 \%$ & $4.0 \%$ & $13.0 \%$ & $22.9 \%$ & $60.2 \%$ \\
\hline wealth & & & & & & & \\
$\quad$ model $E_{0}$ & 1.37 & 0.65 & $0.1 \%$ & $2.2 \%$ & $9.2 \%$ & $23.1 \%$ & $65.4 \%$ \\
$\quad$ data $(\mathrm{SCF})$ & 6.53 & 0.80 & $-0.3 \%$ & $1.3 \%$ & $5.0 \%$ & $12.2 \%$ & $81.7 \%$ \\
\hline \hline
\end{tabular}

Note: $c v$ refers to coefficient of variation. $q_{1}, \ldots, q_{5}$ refer, for earnings and wealth, to the share held by all people in the corresponding quintile with respect to the total. However, for hours it is the average number of hours worked by people in the corresponding quintile. Statistics from SCF correspond to the 1998 wave and are quoted from Budría, Díaz-Giménez, Quadrini, and Ríos-Rull (2002). Statistics from SCF correspond to the 2002 wave.

close to data. The second panel reports some statistics for the distribution of labor earnings. I use data from two different sources: the CPS, computed by myself, and the Survey of Consmer Finances (SCF), quoted from Budría, Díaz-Giménez, Quadrini, and Ríos-Rull (2002). The differences between the two data sources are very large. There is a number of reasons that generate differences between the CPS and the SCF sources. First, the CPS is individual-based whereas the SCF is household-based. Second, the SCF oversamples rich households to better capture the upper tail of the income distribution. In addition, my own treatment of the CPS data in order to construct measurements comparable to the magnitudes in the model necessarily generates big differences. First, the statistics from CPS are cleaned from fixed heterogeneity in order to be comparable with the model, whereas the statistics from SCF are not. Second, the sample selection for the CPS is restricted to workingage individuals who supply positive hours in 2002 whereas the SCF contains the whole population. Comparing the model to data, we observe that the model does a very good job in replicating the distribution of labor earnings from the CPS. The average earnings at each quintile are very similar. The main difference arises in the top quintile, which earn more labor income in the model. This is reflected in the coefficient of variation and the gini index, which are bigger for the model economy. Of course, and by construction, the model falls short from the observed concentration of the earnings distribution as measured in the SCF. Finally, due to the lack of fixed heterogeneity the overall concentration of the wealth distribution is much lower than 
in data. The model generates a gini index for the wealth distribution equal to 0.65 whereas the equivalent statistics in the SCF is 0.80 .

\section{Results}

The basic economic experiment performed in this paper is the comparison of allocations between the steady state equilibrium of an incomplete markets economy calibrated to reproduce key statistics from data and the allocations of the steady state equilibrium of a complete markets counterpart. However, as stated in section 2.5, there are multiple complete markets economies to use. I will solve for the complete markets economy that arises after a full transition from the incomplete markets economy to the new complete markets steady state equilibrium. Additionally, in section $5.4 \mathrm{I}$ also present results for the complete markets economy that corresponds to an equal-weight planner's problem. ${ }^{20}$

\subsection{Aggregate hours and labor productivity}

The complete and incomplete markets economies imply distinctly different household's behavior in the labor market. A first evidence of this are the disparate measures of aggregate hours worked and aggregate labor in the different model economies. In table 3 we see that aggregate hours worked are much higher in the incomplete markets economy $(I M)$ than in its complete markets counterpart $(C M)$. In the incomplete markets economy aggregate hours are calibrated to reproduce the 0.33 value found in data. In the complete markets economy aggregate hours equal 0.28 , which implies that aggregate hours worked in the incomplete markets economy are about $18 \%$ higher than they would be in a world with state contingent assets.

Table 3: Aggregate labor and productivity.

\begin{tabular}{lcccc}
\hline \hline & $H$ & $L$ & $L / H$ & $Y / H$ \\
\hline$I M$ economy & 0.33 & 0.33 & 1.00 & 3.50 \\
$C M$ economy & 0.28 & 0.35 & 1.24 & 3.96 \\
$I M / C M-1$ & $18.0 \%$ & $-4.7 \%$ & $-19.3 \%$ & $-11.5 \%$ \\
\hline \hline
\end{tabular}

In contrast to this result, aggregate labor is lower in the incomplete markets economy. Table 3 shows that aggregate labor is $4.7 \%$ lower in the incomplete mar-

\footnotetext{
${ }^{20}$ See appendices A.1 and A.2 for details on how to solve for these two complete markets economies.
} 
kets economy. The fact that hours worked are higher and aggregate labor is lower in the incomplete markets economy indicates that the average efficiency per hour worked must be lower in the incomplete markets economy. Indeed, we observe this in the third column of table 3. The average amount of efficiency labor units per hour worked in the incomplete markets economy is 1.00 whereas it is 1.24 in the complete markets economy: average efficiency per hour worked is $19.3 \%$ lower under incomplete markets. Additionally, we also see in table 3 that the total productivity per hour worked, measured as output per hour, is markedly lower in the incomplete markets economy, $11.5 \%$ less.

The reasons for these results are quite straightforward. Under complete markets, households base the variation of hours worked across states entirely on the variation of efficiency units. The first order condition for the labor decision is given by equation (6). In the complete markets economy the consumption level is the same regardless of the realization of $\varepsilon$. Therefore, $l$ adjusts to movements on $\varepsilon$ alone. In other words: the realization of the idiosyncratic shock does not carry any wealth effect and the variations of hours worked respond only to the substitution effect. However, under incomplete markets the realization of the shock does change consumption levels. Low $\varepsilon$ implies low consumption and therefore high marginal utility of consumption. Therefore, a household with low $\varepsilon$ chooses to work more in the incomplete markets economy due to the high value of the wage obtained. This effect is strengthened when the idiosyncratic shocks are persistent. Overall, the average productivity per hour worked is lower in the incomplete markets economy because labor is used to smooth consumption fluctuations across states and therefore does not fully respond to variations in productivity.

To illustrate this latter point, let us look at the graphical counterpart of equation (6). In figure 1 I plot the policy function for hours worked in the incomplete markets economy. ${ }^{21}$ We observe that, other things equal, work effort increases with the efficiency endowment and decreases with wealth. However, as shown in table 4, the correlation between efficiency units and assets is high, 0.51. This means that in equilibrium good shocks are associated to high wealth and bad shocks to low wealth. The reason behind this is that shocks are very persistent. Households receive long series of good or bad shocks, which make them accumulate or deplete wealth. Then, in equilibrium, we observe that many of the very productive households are also wealth rich and therefore they do not work much because the marginal value of each unit of consumption is low. On the other hand, we observe that many of the low

\footnotetext{
${ }^{21}$ In terms of the policy functions defined in section 2.4 it corresponds to $1-g^{l}(\varepsilon, a)$.
} 
Figure 1: Policy functions for hours under incomplete markets.

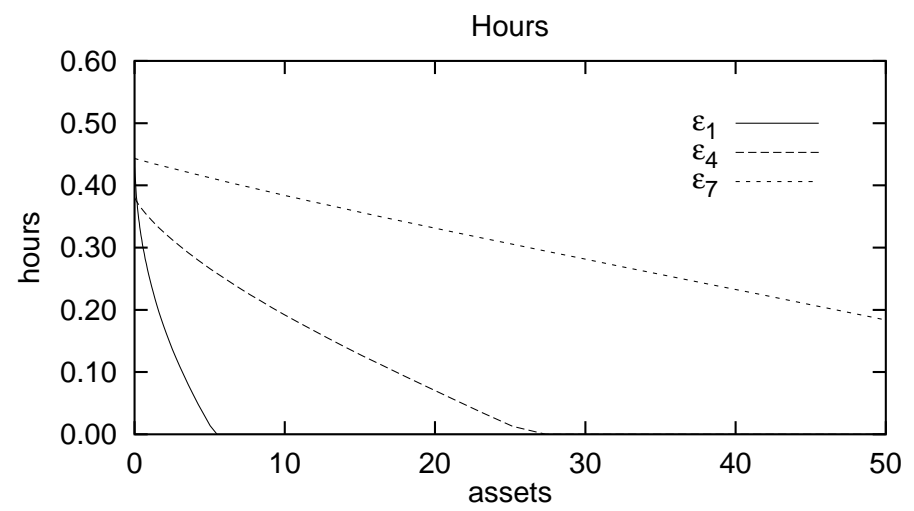

Note: Productivity shocks are labelled such that $\varepsilon_{7}>\varepsilon_{4}>\varepsilon_{1}$. Hours are reported as fraction of total available time. Assets are reported in levels, where 1.15 corresponds to the (per capita) output of the economy.

productive households are also wealth poor, supplying a lot of hours in spite of their low return because the marginal value of an extra unit of consumption is very high for them. This results in a low correlation of wages and hours and a low ratio of aggregate units of labor to aggregate hours. ${ }^{22}$ In contrast, under complete markets the correlation between wealth and hours worked is zero and the correlation between hours and labor productivity is as high as 0.74 .

Table 4: Correlations.

\begin{tabular}{lcc}
\hline \hline & $\operatorname{corr}(a, \varepsilon)$ & $\operatorname{corr}(h, \varepsilon)$ \\
\hline$I M$ economy & 0.51 & 0.02 \\
$C M$ economy & 0.00 & 0.74 \\
\hline \hline
\end{tabular}

Marcet, Obiols-Homs, and Weil (2003), in a related work, hold that hours worked are lower under incomplete markets. In a similar model, they set up household uncertainty as a work opportunity. Households have a choice of hours only if given a (stochastic) work opportunity. These authors find that the number of hours worked will be smaller in an incomplete markets economy because employed workers are richer in the incomplete markets world than in a complete markets economy and therefore consume more leisure. Of course, the unemployed are poorer but they do not supply hours of work. Their setting, therefore, does not allow for substitution of labor across different states of the world. This is the main channel operating here:

\footnotetext{
${ }^{22}$ The exact amount in which this happens is chosen by targeting the 0.02 value in data of the correlation between hours and wages.
} 
complete markets allow households to work many hours when the market return is high and work few or none when the market return is low. The substitution of labor across states in the complete markets economies makes the average return per hour worked much higher and therefore lifetime income higher for everybody. Households are hence richer in the complete markets economies and this wealth effect makes them demand more leisure.

\subsection{Precautionary savings or working longer hours?}

The first column in table 5 reports precautionary savings. ${ }^{23}$ Precautionary savings equals $18.6 \%$, which means that $18.6 \%$ of aggregate capital is there due to the lack of markets to insure against idiosyncratic risk. ${ }^{24}$ Is this a a big or a small number? In the second column of table 5 I report a similar statistic but instead of measuring it over aggregate capital I do it over the capital to labor ratio. This would be the type of precautionary savings captured by models without labor choice since it directly arises from the lower marginal product of capital in the incomplete markets economy. In a model without labor choice, the whole difference between capital labor ratios would be imputed to aggregate capital. We can see that precautionary savings measured over capital labor ratios are higher, up to $22.4 \%$. This is the type of effect highlighted by Aiyagari (1994) and it is solely due to the uninsurable variation of labor earnings when the markets are incomplete. ${ }^{25}$

Table 5: Precautionary savings and precautionary hours.

\begin{tabular}{cccc}
\hline \hline & $K$ & $K / L$ & $H$ \\
\hline $1-C M / I M$ & $18.6 \%$ & $22.4 \%$ & $15.2 \%$ \\
\hline \hline
\end{tabular}

Finally, in the third column of table 5 I report an equivalent statistic computed

\footnotetext{
${ }^{23}$ I measure precautionary savings as the difference between aggregate capital in the incomplete markets economy and aggregate capital in a complete markets economy, relative to aggregate capital in the incomplete markets economy. This measure can be interpreted as the fraction of capital in the incomplete markets economy that is there due to the lack of state contingent markets.

${ }^{24}$ Within the general equilibrium literature, measurements of precautionary savings range from $3 \%$ to more than $100 \%$ of total wealth. The wide range of estimates is explained by the size and persistence of the non-permanent component of the idiosyncratic uncertainty in the earnings process that different authors consider. See Díaz, Pijoan-Mas, and Ríos-Rull (2003) and references therein for details.

${ }^{25}$ According to the literature of precautionary savings in partial equilibrium it is actually the interaction of uncertainty with the convexity of the marginal utility what matters. However, with borrowing constraints we obtain precautionary savings regardless of the sign of the third derivative of the utility function. See Aiyagari (1994) or Huggett and Ospina (2001) for details.
} 
over aggregate hours. That is to say, I report the fraction of hours worked in the incomplete markets economy in excess of the hours worked in the complete markets counterpart. I find that $15.2 \%$ of the hours worked in the incomplete markets economy are due to lack of insurance. Therefore, we observe that precautionary hours are in the same order of magnitude as precautionary savings albeit slightly smaller; households seem to be using work effort as much as savings in order to smooth their consumption profiles. Incidentally, note that the use of work effort as an instrument to avoid fluctuations in consumption is different from the concept of precautionary hours highlighted by Flodén (2005). This author refers to the use of hours of work before uncertainty is realized. In our model economy individuals choose work effort once they know the realization of their labor market productivity.

\subsection{The size of the economy}

The standard result that incomplete markets economies are always bigger in terms of both capital and output (as pointed out by Huggett (1993) or Aiyagari (1994)) is obtained for economies where labor is exogenous and thus it does not change when we modify either the market structure or the amount of uncertainty. Therefore, a higher capital to labor ratio necessarily implies higher aggregate capital and thence higher aggregate output and higher aggregate consumption. However, once we allow households to adjust labor supply, the higher capital to labor ratio under incomplete markets does not necessarily lead to a higher aggregate capital. And higher aggregate capital does not necessarily lead to higher output either. Furthermore, higher aggregate output does not necessarily imply higher aggregate consumption.

Table 6: The size of the economy.

\begin{tabular}{lcccc}
\hline \hline & $Y$ & $C$ & $K$ & $L$ \\
\hline$I M$ economy & 1.16 & 0.87 & 3.47 & 0.33 \\
$C M$ economy & 1.11 & 0.87 & 2.83 & 0.35 \\
$I M / C M-1$ & $4.4 \%$ & $-0.6 \%$ & $22.8 \%$ & $-4.7 \%$ \\
\hline \hline
\end{tabular}

Table 6 reports the aggregate allocations of the economy. We see that aggregate output is $4.4 \%$ larger under the incomplete markets case. However, as it will be shown in section 5.3, we can easily parameterize an incomplete markets economy that generates aggregate output smaller than in its complete markets counterpart. The change in aggregate output can be decomposed into its two determinants, aggregate labor and aggregate capital. We have already seen that aggregate labor is smaller 
and aggregate capital is bigger in the incomplete markets economies.

Finally, in spite of larger aggregate output, the incomplete markets economy displays an amount of aggregate consumption slightly below what is obtained in the complete markets setup. Does this mean that the incomplete markets economy is dynamically inefficient? This cannot be the case since the interest rate is positive. What happens is the following. Steady state consumption $C$ is equal to $F(K, L)-$ $\delta K$. With exogenous labor supply, the fact that the incomplete markets economy has more capital and lower consumption necessarily implies that $F_{K}<\delta$ and therefore that the economy is dynamically inefficient. However, with endogenous labor a fall in aggregate labor $L$ can make output increase less than $\delta K$ while still having $F_{K}>\delta$. This is indeed what happens.

\subsection{Welfare gains}

In these type of economies, households have two costly margins of adjustment in order to smooth their consumption profiles. On the one hand, they can save in advance so that when bad times come there is a buffer stock of assets to avoid large drops in consumption. Building precautionary savings is costly because it implies saving at an interest rate lower than the subjective time discount rate. On the other hand, households can adjust their work effort when a shock is realized. If wages fall, the household can prevent consumption from falling too much by working additional hours and thus making sure that labor income does not suffer so much. This is costly because it implies working longer hours precisely when the household is less productive. A natural quantitative question in this framework is whether these costs are big. Or in other words, is the absence of state contingent bonds to trade the idiosyncratic labor market risk very costly?

To answer this question I compute the percentage consumption increase that we should give forever to every individual in the incomplete markets world for her to be indifferent between the incomplete markets world and waking up in a complete markets economy in steady state with the same level of assets and labor market productivity. Of course, these welfare measure will differ heavily among households. Households with very few assets are badly self-insured, so we should expected them to obtain sizeable gains of complete markets. The reason is double. First, they will be able to eliminate fluctuations in consumption. This is the pure insurance effect. Second, they will be able to work long hours when more productive and enjoy leisure when less productive. These are the gains of a more efficient allocation of 
Figure 2: Welfare gains.
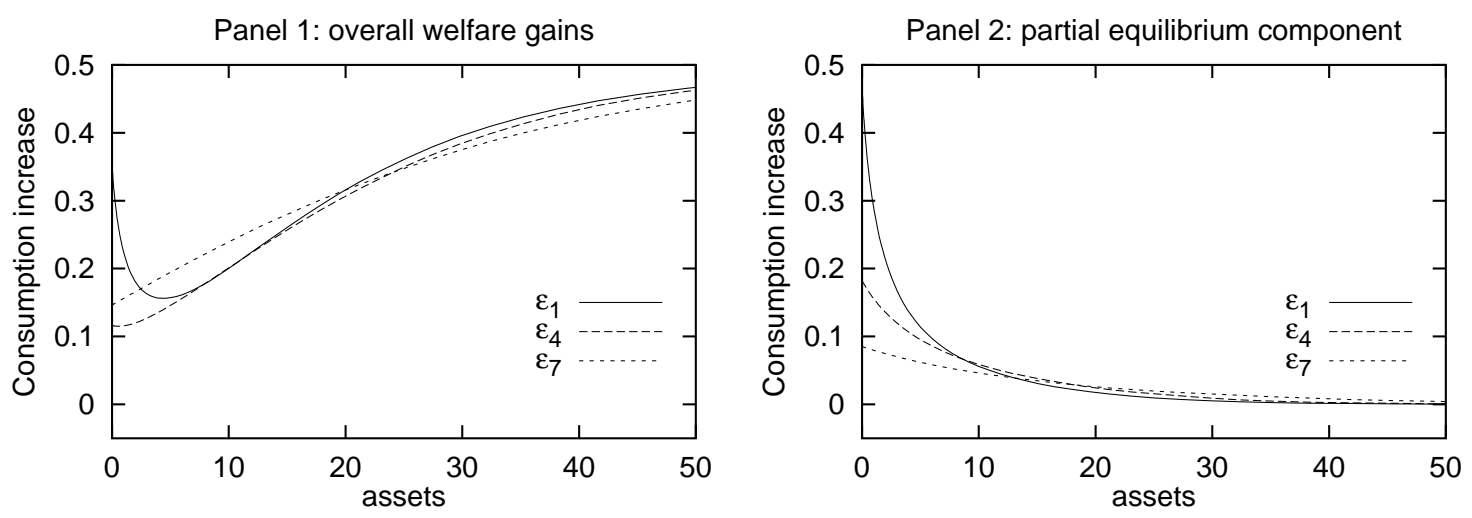

Note: Productivity shocks are labelled such that $\varepsilon_{7}>\varepsilon_{4}>\varepsilon_{1}$. Consumption increase is the relative increase in consumption. Assets are reported in levels, where 1.15 corresponds to the (per capita) output of the economy.

work effort. In contrast, households with large stocks of asset are very well selfinsured in the incomplete markets economy. They are not expected to gain much from moving into a world with insurance markets because their consumption profiles are already quite smooth and because their work effort already tracks productivity. However, the world with state contingent bonds differs from the incomplete markets economy not only in the insurance technology, but also in the equilibrium prices. Precisely, since the capital to labor ratio is smaller in the complete markets economy, the interest rate will be higher and the wage rate lower than in the incomplete markets economy. Therefore, in contrast to the partial equilibrium effects, assetrich households benefit more from moving to complete markets than asset-poor households because the change in prices is beneficial to them. Hence, the relative size of the partial equilibrium effects and the price effect will determine whether the welfare costs of market incompleteness are increasing or falling with the level of assets.

In order to decompose the welfare gains into their partial equilibrium and their price components, I will define a second measure of welfare change. I solve the household problem under incomplete markets for the pair of prices of complete markets. Then, I look for the relative increase in consumption to be given to every individual of this world such that they are indifferent with the complete markets economy. This welfare measure gives the partial equilibrium effect. Figure 2 plots individual welfare gains against assets for three different labor market productivity shocks. Panel 1 shows total welfare increase whereas panel 2 only shows the partial 
equilibrium component. The difference between them corresponds to the price effect. As stated above, the welfare benefits of complete markets solely due to partial equilibrium effects are the biggest for the asset poor and decrease monotonically with the level of assets. Not shown in the graphs, the welfare benefits due to the change in prices increase monotonically with assets. The overall effect is a combination of both. For instance, for the lowest realization of the shock, $\varepsilon_{1}$, the partial equilibrium components dominate for low levels of assets as the welfare gains of complete markets decrease with assets. However, there is a point where the individual is quite well self-insured and the change in prices is more important: from here onwards welfare gains of complete markets increase with assets.

Table 7: Individual welfare gains.

\begin{tabular}{lrrrrrr}
\hline \hline & \multicolumn{6}{c}{ Average equivalent variation of consumption } \\
& all & \multicolumn{1}{c}{$q_{1}$} & \multicolumn{1}{c}{$q_{2}$} & \multicolumn{1}{c}{$q_{3}$} & \multicolumn{1}{c}{$q_{4}$} & \multicolumn{1}{c}{$q_{5}$} \\
\hline Full model & $16.1 \%$ & $11.5 \%$ & $12.5 \%$ & $14.6 \%$ & $16.8 \%$ & $25.2 \%$ \\
PE component & $15.2 \%$ & $5.5 \%$ & $10.0 \%$ & $13.8 \%$ & $18.4 \%$ & $28.5 \%$ \\
GE component & $0.9 \%$ & $-9.1 \%$ & $-5.9 \%$ & $-1.7 \%$ & $4.3 \%$ & $16.9 \%$ \\
Fixed hours & $9.3 \%$ & $6.3 \%$ & $7.0 \%$ & $8.3 \%$ & $9.9 \%$ & $14.8 \%$ \\
PE component & $9.4 \%$ & $3.4 \%$ & $5.8 \%$ & $8.2 \%$ & $11.2 \%$ & $18.4 \%$ \\
GE component & $-0.1 \%$ & $-7.2 \%$ & $-4.5 \%$ & $-1.3 \%$ & $2.7 \%$ & $9.6 \%$ \\
Transition & $16.5 \%$ & $12.9 \%$ & $13.9 \%$ & $14.6 \%$ & $17.5 \%$ & $23.5 \%$ \\
\hline \hline
\end{tabular}

Note: all refers to the average over the whole population. $q_{1}, \ldots, q_{5}$ refer to the average within the corresponding quintile. PE and GE mean partial and general equilibrium respectively.

The actual values of these welfare gains are impressive. For instance, households with no assets and the lowest market productivity enjoy a welfare increase in complete markets equivalent to a $35 \%$ increase in consumption. Yet, for this type of individuals the change in prices implies income losses; without the price effect their welfare gains would be as large as $47 \%$. Table 7 reports the average over the whole population of these welfare gains: they turn out to be as big as 16.1\%. Looking at the decomposition of the welfare gains, the average of the partial equilibrium component is $15.2 \%$ and the average of the price component is $0.9 \%$. Therefore, the bulk of the aggregate welfare gains of complete markets is due to its partial equilibrium effects, with the welfare benefits due to the change in prices being more or less offset among individuals.

It is interesting to note the small size of the price component. This is the result of two counteracting forces. First, the price changes (interest rate increase and wage decrease) imply shifting resources from low consumption individuals to high consumption individuals. Low consumption individuals own few assets and 
are intensive in labor income. Therefore the price change decreases the share of output they receive. In contrast, high consumption individuals are asset rich and work very little. Therefore, they benefit with the price changes. Since marginal utility is decreasing in consumption, this redistribution of resources generates, on average, welfare losses. ${ }^{26}$ Second, the change in prices also accounts for the change in aggregate allocations of the economy. The complete markets economy allows larger aggregate consumption and leisure. This brings welfare gains. As seen, these two effects turn out to offset each other. This result adds value to the work by Heathcote, Storesletten, and Violante (2005). In a complementary work, they obtain analytical expressions for the aggregate welfare gains of introducing insurance markets. The cost they pay is that their results only account for the partial equilibrium component. However, what we see is that for the aggregate welfare gains, the general equilibrium effect hardly matters.

A further question about the welfare gains is the relative importance of the use of labor as a self-insurance mechanism. Recall that the productivity gains in the complete markets economy are due to the fact that households use their work effort to exploit the variance in labor market productivity. In order to measure the relative importance of labor flexibility, I perform the following experiment. I take the households in the incomplete markets economy and force all of them to work a fixed amount of time equal to the calibrated average number of hours, 0.33. I solve for the new steady state equilibrium. Then, I compute the same welfare measures as before, with the complete markets economy being also forced to have a fixed labor equal to the average of 0.33. How big are the welfare gains from moving to the complete markets world? Table 7 reports this figure: on average, $9.3 \%$. This implies that a $42 \%$ of the welfare gain of complete markets is due to the possibility of adjusting labor supply. As before, we can separate the welfare gains into a partial equilibrium and a price component. In the fixed labor model this is particularly informative because the partial equilibrium component is solely due to insurance, with no possibility of labor reallocation. I find the average of the partial equilibrium gains to be equal to $9.4 \%$. Therefore, $62 \%$ of the the partial equilibrium gains are due to the pure insurance effect and $38 \%$ are due to the labor reallocation opportunities. Hence, I conclude that the substitution of hours of work across states in the complete markets setting is a major source of welfare improvement.

\footnotetext{
${ }^{26}$ This idea is emphasized by Dávila, Hong, Krusell, and Ríos-Rull (2005), who show that due to distributional effects the actual level of aggregate capital in an incomplete markets economy is too low.
} 


\subsection{The transition}

The comparison between steady states can be complemented by looking at how the economy evolves from the incomplete markets setting to the steady state equilibrium with complete markets. In appendix A.2 I explain how to solve for the transition.

Figure 3: Transition of aggregate variables
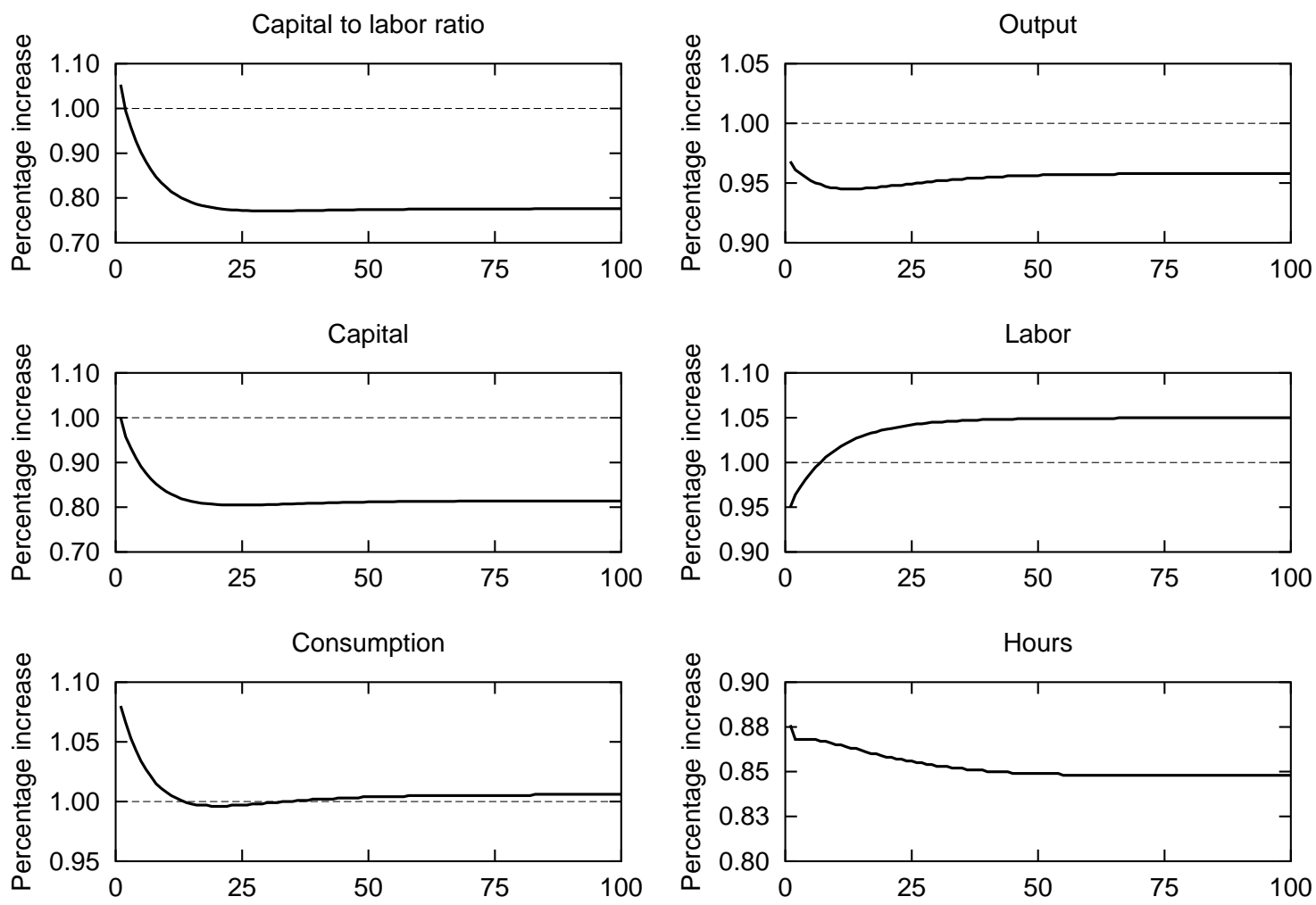

Note: Variables are scaled relative to their level in the incomplete markets economy. The dashed line serves as reference for the incomplete markets level.

In figure 3 I show the simulated transition paths for the capital to labor ratio, aggregate output, aggregate capital, aggregate labor, aggregate consumption and aggregate hours of work. We observe that in period $t=1$, once we allow households to trade Arrow securities, the capital to labor ratio jumps up. Then it declines gradually to its new steady state value. The reason is that at $t=1$ capital is predetermined and only aggregate labor adjusts. As the transition goes on, aggregate capital falls to its new steady state level and aggregate labor increases. It is also important to note that at $t=1$ consumption jumps up and gradually declines to its new steady state level. ${ }^{27}$ This is particulary good news: since in the new steady

${ }^{27}$ Nonetheless, it falls slightly below its incomplete markets level for a while, tracking the $\mathrm{u}-$ 
state aggregate capital will be lower, some extra consumption can be afforded during the transition. Then, once the economy stabilizes in the new steady state, aggregate consumption reamains slightly above its initial value. In contrast, we observe that work effort is higher at the beginning of the transition and it gradually declines to its complete markets steady state level. Therefore, leisure during the transition is lower than in the final steady state. Hence, in terms of welfare, accounting for the transition implies considering a time period where consumption is higher and leisure lower than in the final steady state. Which of these effects prevails? In the third row of the first panel in table 7 I report the average over the whole population and within each quintile of the welfare increase when explicitly accounting for the transition. I find this average to be equal to $16.5 \%$ of consumption in the incomplete markets economy. This is 0.4 percentage points more.

\section{Robustness}

In this section I want to show that, although there may be important quantitative adjustments, the qualitative results prevail once we change certain parameters of the model. In section 5.1 I show that relaxing the borrowing constraints of households in the incomplete markets economy does not affect the results. This is an important exercise since the tightness of borrowing constraints is a crucial determinant of the available financial trades for an incomplete markets economy. Next, in section 5.2 I look at changes in $\nu$, the parameter driving the intertemporal elasticity of substitution of labor. I do so because this is a parameter value over which there are multiple estimates that are somewhat different from the values chosen in this paper. With a more inelastic labor supply the quantitative results are less impressive. However, changes in $\nu$ do not modify the main qualitative results of the paper. In section 5.3 I use a more persistent wage process. Finally, in section 5.4 I solve for a different complete markets economy and for the representative agent economy.

\subsection{The borrowing constraints}

A possible objection to the results shown so far is that allowing households to borrow increases the ability to move resources from high wage periods to low wage periods and therefore may diminish the use of hours as a smoothing mechanism. To probe this issue, I calibrate a new economy to the same statistics from data as before. In shaped profile of output. 
this new economy, households are allowed to borrow an amount equivalent to the average annual income of the economy. ${ }^{28}$

Table 8: Calibration targets and model parameters.

\begin{tabular}{cccccc}
\hline \hline parameter & target & \multicolumn{4}{c}{ calibrated value } \\
& & model $E_{0}$ & $\underline{a}=-1.00 Y$ & $\nu=8.0$ & $H P$ \\
\hline$\sigma$ & $\operatorname{corr}(h, \varepsilon)=0.02$ & 1.458 & 1.514 & 1.412 & 0.992 \\
$\nu$ & $c v(h)=0.22$ & 2.833 & 3.459 & 8.000 & 1.290 \\
$\lambda$ & $H=0.33$ & 0.856 & 0.674 & 0.110 & 1.545 \\
$\beta$ & $K / Y=3.00$ & 0.945 & 0.948 & 0.948 & 0.955 \\
$\theta$ & $w L / Y=0.64$ & 0.640 & 0.640 & 0.640 & 0.640 \\
$\delta$ & $I / Y=0.25$ & 0.083 & 0.083 & 0.083 & 0.083 \\
\hline \hline
\end{tabular}

Note: For the economy with $\nu=8.0$ the $c v(h)$ is kept free and turns out to be 0.09 . For all other economies the model parameters deliver the same 6 statistics.

Table 8 presents the parameter values for this economy together with the ones for the benchmark case (model $E_{0}$ ). The first interesting result is that we need higher curvature households for the borrowing economy to be consistent with the same observed statistics. When households are allowed to borrow, they have a better financial technology to keep a smooth consumption profile and thus they are more inclined to work harder when the shock is good and rest when the productivity is low. Therefore, for the economy to show the low correlation between hours and wages and the given volatility of hours, we need households to be less willing to substitute, that is to say, we need higher $\sigma$ and $\nu$. As table 8 shows, for the economy where households are allowed to borrow up to the average per capita income of the economy $\nu$ equals 3.459. This value implies an intertemporal elasticity of substitution of labor equal to 0.59, almost at the point estimate in data by Domeij and Flodén (2003).

Overall, the quantitative effects of borrowing are only minor. The second panel of table 9 shows that when allowing for borrowing the differences in hours worked between complete and incomplete markets are slightly smaller, although very similar to the ones for the case with no borrowing. A way to interpret this is as follows. With the possibility of borrowing households need to use hours of work as smoothing mechanism to a lesser degree. This implies that for the model to produce the same amount of hours worked as in data we need to decrease $\lambda$, the weight of leisure in the utility function. Then, in complete markets a lower $\lambda$ implies a higher amount of

\footnotetext{
${ }^{28}$ Notice that for this parametric experiment we are not taking into consideration that households may prefer not to work and repudiate the debt and the problems for the existence of a credit market that this would pose.
} 
hours worked. Similarly, the productivity gains of market completeness, measured by both labor efficiency and output per hour worked, barely change.

Table 9: Aggregate allocations.

\begin{tabular}{ccccccc}
\hline \hline & $H$ & $L$ & $L / H$ & $Y / H$ & $Y$ & $C$ \\
\hline model $E_{0}$ & & & & & & \\
$I M$ economy & 0.33 & 0.33 & 1.00 & 3.50 & 1.16 & 0.87 \\
$C M$ economy & 0.28 & 0.35 & 1.24 & 3.96 & 1.11 & 0.87 \\
$I M / C M-1$ & $18.0 \%$ & $-4.7 \%$ & $-19.3 \%$ & $-11.5 \%$ & $4.4 \%$ & $-0.6 \%$ \\
\hline model $\underline{a}=-1.0 Y$ & & & & & & \\
$I M$ economy & 0.33 & 0.33 & 1.00 & 3.50 & 1.16 & 0.87 \\
$C M$ economy & 0.29 & 0.35 & 1.20 & 3.87 & 1.12 & 0.88 \\
$I M / C M-1$ & $14.0 \%$ & $-4.6 \%$ & $-16.3 \%$ & $-9.5 \%$ & $3.2 \%$ & $-1.1 \%$ \\
\hline model $\nu=8.0$ & & & & & & \\
$I M$ economy & 0.33 & 0.33 & 1.00 & 3.50 & 1.15 & 0.87 \\
$C M$ economy & 0.32 & 0.34 & 1.08 & 3.49 & 1.10 & 0.86 \\
$I M / C M-1$ & $4.7 \%$ & $-3.0 \%$ & $-7.3 \%$ & $0.4 \%$ & $5.0 \%$ & $0.6 \%$ \\
\hline model $H P$ & & & & & & \\
$I M$ economy & 0.33 & 0.33 & 1.00 & 3.50 & 1.16 & 0.87 \\
$C M$ economy & 0.26 & 0.36 & 1.39 & 4.64 & 1.21 & 0.94 \\
$I M / C M-1$ & $26.1 \%$ & $-9.2 \%$ & $-28.0 \%$ & $-24.5 \%$ & $-4.7 \%$ & $-7.4 \%$ \\
\hline \hline
\end{tabular}

Regarding precautionary savings, the second row of table 10 shows they fall slightly when we allow for borrowing. Allowing for borrowing preserves the essence of the results: (1) precautionary savings are smaller than measured by a model without labor choice and (2) the increase in hours worked is in the same order of magnitude as the increase in total savings.

Table 10: Precautionary savings and precautionary hours.

\begin{tabular}{lccc}
\hline \hline & $K$ & $K / L$ & $H$ \\
\hline model $E_{0}$ & $18.6 \%$ & $22.4 \%$ & $15.2 \%$ \\
model $\underline{a}=-1.0 Y$ & $15.6 \%$ & $19.4 \%$ & $12.3 \%$ \\
model $\nu=8.0$ & $17.4 \%$ & $19.9 \%$ & $4.5 \%$ \\
model $H P$ & $3.7 \%$ & $12.6 \%$ & $20.7 \%$ \\
\hline \hline
\end{tabular}

Finally, table 11 reports the welfare gains of complete markets. For the borrowing economy the average of welfare gains over the population is $14.6 \%$, only one and a half percentage points below what was measured by means of the economy where no borrowing was allowed. 
Table 11: Individual welfare gains.

\begin{tabular}{lrrrrrr}
\hline \hline & \multicolumn{6}{c}{ Average equivalent variation of consumption } \\
& all & \multicolumn{1}{c}{$q_{1}$} & $q_{2}$ & $q_{3}$ & $q_{4}$ & $q_{5}$ \\
\hline model $E_{0}$ & $16.1 \%$ & $11.5 \%$ & $12.5 \%$ & $14.6 \%$ & $16.8 \%$ & $25.2 \%$ \\
model $\underline{a}=-1.0 Y$ & $14.6 \%$ & $10.2 \%$ & $11.1 \%$ & $13.0 \%$ & $15.5 \%$ & $23.4 \%$ \\
model $\nu=8.0$ & $11.5 \%$ & $8.2 \%$ & $8.9 \%$ & $10.4 \%$ & $12.2 \%$ & $18.0 \%$ \\
model $H P$ & $15.5 \%$ & $12.1 \%$ & $12.6 \%$ & $14.4 \%$ & $16.2 \%$ & $22.1 \%$ \\
\hline \hline
\end{tabular}

Note: all refers to the average over the whole population. $q_{1}, \ldots, q_{5}$ refer to the average within the corresponding quintile.

\subsection{The intertemporal elasticity of substitution of labor}

The quantitative results of the paper depend on the households willingness to substitute leisure and consumption across time and states of the world. This behavior is mainly determined by $\nu$ and $\sigma$. The choice of these parameters, therefore, should be guided by households observed behavior. The parameter $\nu$ is obtained from the observed volatility of hours worked. The parameter $\sigma$ drives the correlation between hours and wages.

However, the intertemporal elasticity of substitution of labor implied by the calibrated $\nu$ in the incomplete markets economy, 0.72, is a bit larger than what other authors have typically estimated. For example, using PSID data MaCurdy (1981) reports estimates for this elasticity between 0.10 and 0.23 . Also using PSID data Altonji (1986) reports an estimation of 0.17. The consensus in the profession seemed to be that this elasticity is very low. ${ }^{29}$ However, as discussed by Domeij and Flodén (2003), estimations that do not take into account the fact that households may be constrained in their borrowing are downward biased. Correcting for borrowing constraints, these authors own estimates put the elasticity around 0.55, just a bit lower than the elasticity implied by the benchmark model and as big as the one implied by the model where borrowing is allowed. ${ }^{30}$

Given the disparity of estimates for $\nu$, an interesting sensitivity analysis is to see how the results change as we modify it. To do so, I will solve for an additional economy. I will choose a high $\nu$ to accord with the low elasticities of labor supply estimated in the empirical literature. In particular, I impose $\nu=8.00$, which yields an elasticity equal to 0.25 . The rest of the parameters will be calibrated in equilibrium as described in section 3 .

\footnotetext{
${ }^{29}$ See Blundell and MaCurdy (1999) and references therein.

${ }^{30}$ See section 5.1 .
} 
Table 8 presents the new calibrated values for the model parameters when I impose $\nu=8$. It may be worth highlighting that the coefficient of variation of hours, an statistic that now is kept free, becomes 0.09. This is not surprising: higher curvature in leisure implies that households substitute labor across time to a lesser extent and therefore the cross-section volatility of hours is lower than the value 0.22 found in data.

As expected, the parameter $\nu$ has a sizeable impact on labor market behavior. The third panel of table 9 shows small differences in the total amount of hours of work between complete and incomplete markets. Likewise, the differences in total efficiency units of labor are also smaller than in the benchmark economy. This makes the average efficiency per hour worked in incomplete markets be just $7 \%$ smaller than under complete markets. With the calibrated $\nu=2.833$ this value was around $19 \%$. If household dislike substituting leisure over time to a large extent, even in complete markets they will choose to work a fairly constant amount of hours every period without tracking their productivity very much. Recall that the major ingredient for the big difference between complete and incomplete markets economies is the willingness to substitute labor across state in a complete markets world.

Regarding precautionary savings, the third row of table 10 shows them to be similar to the benchmark economy. They are still smaller than when measured by capital labor ratios. Even if the size of precautionary savings varies with $\nu$, changes in the curvature have a much larger impact on hours of work than on aggregate savings.

Finally, in the third row of table 11 we observe that the average welfare gains of complete markets equal $11.5 \%$ of consumption in the incomplete markets economy. This is distinctly smaller figure than the $16.2 \%$ measured by the benchmark economy. However, as welfare gains go, it is still a very big number.

\subsection{Wage process}

A key parameter for the quantitative results of this type of economies is the persistence of the wage process. If the process for wages is a white noise, then the use of savings is a very effective tool to smooth out labor market fluctuations. In contrast, if the process for wages is very persistent self insurance is much harder to obtain. In this section I recalibrate the economy to the same key statistics but I allow for a more persistent wage process. I will use a discretization of the process estimated by 
French (2003). ${ }^{31}$ I will call the model economy calibrated to the highly persistence wage process $H P$.

The new parameter values are reported in the last column of table 8. An important difference is that the benchmark economy, with a less persistent process for wages than the economy $H P$, requires higher curvatures to be consistent with the same statistics from data. For the economy $E_{0}$ we obtain $\sigma=1.458$ and $\nu=2.833$. In contrast, for the economy $H P$ we obtain $\sigma=0.992$ and $\nu=1.290$. These differences imply that households in an economy with a very persistent process for wages (economy $H P$ ) are inferred to be more willing to substitute both consumption and leisure intertemporally if they are to display the same behavior as households in an economy where the process for wages is less persistent (economy $E_{0}$ ). The reason is that with a more persistent wage process the use of savings is a worse instrument to insure against fluctuations in income and therefore labor tracks productivity to a lesser degree. This requires lower $\sigma$ and $\eta$ and thus higher willingness to substitute consumption and leisure across time.

We obtain starker quantitative results by use of the model economy calibrated with the more persistent wage process. In the last panel of table 9 we observe that aggregate output is indeed $4.7 \%$ smaller in the incomplete markets economy. This is in utter contrast to the standard results of Aiyagari (1994) or Huggett (1993) without endogenous labor. Aggregate consumption is more than $7 \%$ smaller in the complete markets economy. What happens is the following. With a more persistent wage process we need less curvature to fit the observed labor market behavior. Once we introduce state contingent bonds households are more willing to substitute leisure intertemporally and will profit from good labor market opportunities. This increases the correlation between hours of work and wages and therefore increases labor productivity. In table 9 we see that the average efficiency per hour worked in the complete markets economy equals 1.39 in the economy with the highly persistent wage process compared to the smaller 1.24 in the benchmark economy.

Regarding precautionary savings and work effort, we observe that for the $H P$ economy the excess of hours compared to the complete markets economy is much higher than the excess of assets: whereas precautionary savings are only $3.7 \%$ precautionary hours are $20.7 \%$. In words, if we are to believe that the labor market uncertainty that households face is closer to the one measured by Flodén and Lindé (2001) then the lack of state contingent bonds makes work effort increase almost as

\footnotetext{
${ }^{31}$ See section 3.1.
} 
much as aggregate capital. However, if the labor market uncertainty is closer to the one measured by French (2003), then we should conclude that households basically use work effort to smooth labor market risk with very little recurse to savings.

Finally, the welfare gains of complete markets are $15.5 \%$, in the same order of magnitude as in the benchmark economy. This might come as a surprise since aggregate consumption falls much more than in the benchmark economy. However, notice that work effort is also much smaller in the complete markets economy of the $H P$ model. That is to say: the move to complete markets implies a smaller economy with lower consumption but also with more leisure.

\subsection{A different complete markets economy}

As discussed in section 2.5, there is a number of different complete markets economies consistent with the definition of steady state equilibrium. Throughout the text I have been using the complete markets economy that arises after a full transition to the new steady state. In this section I will present results for a second complete markets economy, one in which all households enjoy the same level of consumption. This is equivalent to an economy where all households have the same permanent income and corresponds to a social planner problem where all households are given the same weight. What I find is that the quantitative results hardly change. Additionally, I also solve for an economy inhabited by a representative agent with a constant labor efficiency endowment equal to the unconditional average of $\varepsilon$. This latter exercise allow us to focus in the difference between providing insurance against labor market uncertainty and eliminating this uncertainty altogether.

Table 12: Aggregate allocations.

\begin{tabular}{lcccccc}
\hline \hline & $H$ & $L$ & $L / H$ & $Y / H$ & $Y$ & $C$ \\
\hline$I M$ economy & 0.33 & 0.33 & 1.00 & 3.50 & 1.16 & 0.87 \\
$C M_{1}$ economy & 0.28 & 0.35 & 1.24 & 3.96 & 1.11 & 0.87 \\
$C M_{2}$ economy & 0.27 & 0.34 & 1.27 & 4.04 & 1.09 & 0.86 \\
$R A$ economy & 0.33 & 0.33 & 1.00 & 3.19 & 1.06 & 0.83 \\
$I M / C M_{1}-1$ & $18.0 \%$ & $-4.7 \%$ & $-19.3 \%$ & $-11.5 \%$ & $4.4 \%$ & $-0.6 \%$ \\
$I M / C M_{2}-1$ & $22.0 \%$ & $-3.4 \%$ & $-20.8 \%$ & $-13.2 \%$ & $5.8 \%$ & $0.8 \%$ \\
$I M / R A-1$ & $-0.3 \%$ & $0.0 \%$ & $0.3 \%$ & $9.9 \%$ & $9.5 \%$ & $4.3 \%$ \\
\hline \hline
\end{tabular}

Table 12 reports the basic aggregate statistics for the new complete markets economy, which I label $C M_{2}$ together with the statistics from the complete markets 
economy I have used throughout the paper, which I label $C M_{1}$, and the representative agent economy, $R A$. Table 13 reports precautionary savings as measured in comparison to $C M_{1}, C M_{2}$ and $R A$.

Table 13: Precautionary savings and precautionary hours.

\begin{tabular}{lccc}
\hline \hline & $K$ & $K / L$ & $H$ \\
\hline comparison with $C M_{1}$ & $18.6 \%$ & $22.4 \%$ & $15.2 \%$ \\
comparison with $C M_{2}$ & $19.7 \%$ & $22.4 \%$ & $18.0 \%$ \\
comparison with $R A$ & $22.4 \%$ & $22.4 \%$ & $-0.3 \%$ \\
\hline \hline
\end{tabular}

I find that the two complete markets economies are quite similar. However, the representative agent economy is not. Table 12 shows that households in the representative agent economy work as much as households in the incomplete markets economy. There are no productivity gains in terms of average efficiency per hour worked, and furthermore output per hour worked is indeed larger in the incomplete markets due to its higher capital level. The complete markets economies and the representative agent economy turn out to be very different. In both cases consumption is equalized across states and therefore marginal propensities to consume are linear in wealth. ${ }^{32}$ However, the representative agent receives always the same efficiency endowment whereas the households in the complete markets economies receive different endowments in different states of the world. Consequently, the representative agent works always the same amount of hours whereas the households in the complete markets world substitute leisure across states to work when they are more productive and to enjoy leisure when they are less productive. The average efficiency unit per hour worked is much larger in the complete markets economies, as seen in table 12. Accordingly, aggregate labor is lower in the representative agent economy and, for the equilibrium to hold, so is aggregate capital. In the words of Heathcote, Storesletten, and Violante (2005), uncertainty generates opportunities. In the complete markets economy households benefit from the variance of income shocks while keeping smooth consumption. In the representative agent economy the variance of shocks is gone. While this is good in terms of keeping a smooth consumption profile it prevents households from exploiting labor market opportunities.

\footnotetext{
${ }^{32}$ As opposed to the convex consumption policies that arise with uninsured idiosyncratic risk.
} 


\section{Conclusions}

Many different empirical studies show that households face a substantial amount of idiosyncratic risk in their labor earnings. Since households cannot typically write insurance contracts contingent on the realization of their labor market productivity, they need to self insure against wage fluctuations. The precautionary savings literature has focused so far on the use of savings as a unique self-insurance mechanism. However, there is another potentially very important margin of adjustment once uncertainty has been realized, namely the choice of hours of work. In this paper I use the standard neoclassical growth model with heterogeneous agents to measure the changes in economic aggregates that arise due to the lack of markets to insure against idiosyncratic labor productivity risk. In contrast to the previous literature I explicitly consider the role of labor supply as a smoothing mechanism.

The quantitative exercise reveals that the introduction of complete markets produces very important changes in the labor market behavior. Aggregate hours of work are eighteen percent higher and labor productivity eleven percent lower in the economy without insurance. In the incomplete markets equilibrium workers spend many hours working when they are less productive because for them the marginal product of consumption is very high. Households could avoid this by raising their precautionary savings. They choose to make an extensive use of labor supply as a self-insurance mechanism against wage fluctuations. As an illustration, in this economy precautionary savings account for eighteen percent of aggregate capital. This figure is in the same order of magnitude as the excess of hours of work of the incomplete markets economy with respect to the complete markets economy.

Overall, the welfare gains of complete markets are remarkably high, equivalent to a $16 \%$ increase in lifetime consumption. Most of the aggregate welfare gains come solely from partial equilibrium effects. First, in the complete markets economy household enjoy full insurance and therefore avoid consumption fluctuations. This is the type of welfare gains that one has in mind when thinking about complete markets. Second, there are efficiency gains in the allocation of labor effort. Households choose to work longer hours when more productive and enjoy leisure when less. I find this latter effect to account for about $40 \%$ of the aggregate welfare gains of complete markets. Finally, the general equilibrium effects on aggregate welfare are small. The reason is that while the increase in labor productivity, consumption and leisure suggest large potential gains, the change in prices also imply a redistribution of resources from asset-poor to asset-rich individuals that bring losses in aggregate 
welfare. 


\section{References}

AiYagari, S. R. (1994): "Uninsured Idiosyncratic Risk, and Aggregate Saving," Quarterly Journal of Economics, 109(3), 659-684.

AltonjI, J. (1986): "Intertemporal Substitution in Labor Supply: Evidence from Micro Data," Journal of Political Economy, 94(3), S176-S215.

Blundell, R., And T. MaCurdy (1999): "Labor Supply of Men: A Review of Alternative Approaches," in Handbook of Labor Economics, ed. by O. Ashenfelter, and D. Card, vol. 3. Elsevier Science Publishers.

Budría, S., J. Díaz-Giménez, V. Quadrini, and J.-V. Ríos-Rull (2002): "New Facts on the U.S. Distribution of Earnings, Income and Wealth," Federal Reserve Bank of Minneapolis Quarterly Review, 26(3), 2-35.

CARD, D. (1991): "Intertemporal Labor Supply: an Assessment," NBER Working Paper 3602.

Castañeda, A., J. Díaz-Giménez, and J.-V. Ríos-Rull (2003): "Accounting for U.S. Earnigns and Wealth Inequaltiy," Journal of Political Economy, 111(4), 818-857.

Dávila, J., H. Hong, P. Krusell, and V. Ríos-Rull (2005): "Constrained Efficiency in the Neoclassical Growth Model with Uninsurable Idiosyncratic Shocks," PIER Working Paper 05-023.

Díaz, A., J. Pijoan-Mas, and V. Ríos-Rull (2003): "Precautionary Savings and Wealth Distribution Under Habit Formation Preferences," Journal of Monetary Economics, 50(6), 1257-1291.

DomeiJ, D., And M. FlodÉn (2003): "The Labor-Supply Elasticity and Borrowing Constraints: Why Estimates are Biased.," Mimeo.

FlodÉn, M. (2005): "Labor Supply and Saving under Uncertainty," Forthcoming, Economic Journal.

FlodÉn, M., AND J. LindÉ (2001): "Idiosyncratic Risk in the United States and Sweden: Is There a Role for Government Insurance?," Review of Economic Dynamics, 4, 406-437.

French, E. (2003): "The Effects of Health, Wealth and Wages on Labor Supply and Retirement Behavior," Mimeo, Federal Reserve Bank of Chicago.

Gorman, W. M. (1953): "Community Preference Fields," Econometrica, 21(1), 63-80.

Heathcote, J., K. Storesletten, and G. Violante (2004): "The Macroeconomic Implications of Rising Wage Inequality in the US," Mimeo. 
(2005): "Insurance and Opportunities: the Welfare Implications of Rising Wage Dispersion," Mimeo.

Hopenhayn, H., and E. C. Prescott (1992): "Stochastic Monotonicity and Stationary Distributions for Dynamic Economies," Econometrica, 60(6), 13871406 .

Huggett, M. (1993): "The Risk Free Rate in Heterogeneous-Agents, Incomplete Insurance Economies," Journal of Economic Dynamics and Control, 17(5/6), 953970.

Huggett, M., And S. Ospina (2001): "Aggregate Precuationary Savings: When is the Third Derivative Irrelevant?," Journal of Monetary Economics, 48(2), 373396.

Kubler, F., And K. Schmedders (2001): "Incomplete Markets, Transitory Shocks and Welfare," Review of Economic Dynamics, 4(4), 747-766.

Low, H. (2005): "Self-Insurance in a Life-cycle Model of Labor Supply and Savings," Review of Economic Dynamics, 8(4), 945-975.

MaCurdy, T. E. (1981): "An Empirical Model of Labor Supply in a Life-Cycle Setting," Journal of Political Economy, 89(6), 1059-85.

Maliar, L., and S. Maliar (2003): "The Representative Consumer in the Neoclassical Growth Model with Idiosyncratic Shocks," Review of Economic Dynamics, 6(2), 362-380.

Marcet, A., F. Obiols-Homs, and P. Weil (2003): "Incomplete Markets, Labor Supply and Capital Accumulation," Unpublished manuscript, Universitat Pompeu Fabra.

Parker, S., Y. Belghitar, and T. Barmby (2005): "Wage Uncertainty and the Labour Supply of Self-Employed Workers," Economic Journal, 115, 190-207.

Tauchen, G. (1986): "Finite State Markov-Chain Approximations to Univariate and Vector Autoregressions," Economics Letters, 20(2), 177-181. 


\section{Appendix}

\section{A Solving for the complete markets economies}

In this appendix I explain the nature of and how to solve for the two chosen complete markets economies.

\section{A.1 Equal consumption}

The easiest complete markets characterization to solve is one in which all households enjoy the same level of consumption. The steady state equilibrium for this economy is fully characterized by the following equations:

1. The steady state condition

$$
\beta\left(1+F_{K}(K / L)-\delta\right)=1
$$

2. The $n_{\varepsilon}$ optimal decisions of hours

$$
l^{\nu}=\frac{\lambda}{F_{L}(K / L) \varepsilon} c^{\sigma}
$$

which can be written as a function $l(c, \varepsilon)$.

3. The $n_{\varepsilon}$ budget constraints

$$
c+\beta \sum_{\varepsilon^{\prime}} \Gamma_{\varepsilon \varepsilon^{\prime}} b\left(\varepsilon^{\prime}\right)=b(\varepsilon)+F_{L}(K / L) \varepsilon(1-l(c, \varepsilon))
$$

where the optimal decision of consumption is included by imposing $b(\varepsilon)=$ $b^{\prime}(\varepsilon)$.

4. The market clearing conditions for the production inputs

$$
\begin{aligned}
L & =\sum_{\varepsilon \in \Upsilon} \varepsilon(1-l(c, \varepsilon)) \bar{\Gamma}(\epsilon) \\
K & =\beta \sum_{\varepsilon \in \Upsilon} \bar{\Gamma}(\varepsilon) b(\varepsilon)
\end{aligned}
$$

where $\bar{\Gamma}$ is the stationary distribution of shocks.

Notice that we have already substituted the pair of prices $\{w, r\}$ and the pricing function $q\left(\varepsilon, \varepsilon^{\prime}\right)$ by their equilibrium conditions. This set of equations exhaust the definition of equilibrium stated in section 2.5. We have $2 n_{\varepsilon}+3$ equations and the same number of unknowns: $K, L, c, b(\varepsilon)$ and $l(c, \varepsilon)$. 


\section{A.2 The complete markets economy that arises after the transition}

In the complete markets steady state that arises after the transition, every individual type $\left\{\varepsilon_{1}, a_{1}\right\}$ in the incomplete markets economy will end up with a different level of consumption $c^{*}\left(\varepsilon_{1}, a_{1}\right)$. For every possible $c^{*}\left(\varepsilon_{1}, a_{1}\right)$, equations (9) and (8) define the choices of Arrow securities and leisure in the new steady state. We need to find out this function $c^{*}\left(\varepsilon_{1}, a_{1}\right)$.

So, let's start by assuming that the transition takes $T$ periods and that we know the sequence of prices $\left\{r_{t}, w_{t}\right\}_{1}^{T}$. Note that the Euler equation for consumption at any point $t$ is given by,

$$
c_{t+1}=\beta\left(1+r_{t+1}\right) c_{t}
$$

Therefore, we have the relationship:

$$
c^{*}\left(\varepsilon_{1}, a_{1}\right)=\beta^{T-1} \Pi_{t=2}^{T}\left(1+r_{t}\right) c_{1}\left(\varepsilon_{1}, a_{1}\right)
$$

where $t=1$ is the period in which we start the transition. The budget constraint in this first period will be,

$$
c_{1}\left(\varepsilon_{1}, a_{1}\right)+\sum_{\varepsilon_{2}} q\left(\varepsilon_{1}, \varepsilon_{2}\right) b_{2}\left(\varepsilon_{2}\right)=w_{1} \varepsilon_{1}\left(1-l_{1}\left(\varepsilon_{1}, a_{1}\right)\right)+a_{1}\left(1+r_{1}\right)
$$

with these two last expressions and the sequence of equilibrium prices we can obtain $c^{*}$ for every type $\left\{\varepsilon_{1}, a_{1}\right\}$ in the economy and also the corresponding choices of leisure and Arrow securities as stated by equations (9) and (8).

What we need to find now is the sequence of prices during the transition. We can solve the following fixed point problem. Given a sequence $\left\{r_{t}^{0}, w_{t}^{0}\right\}_{t=1}^{T}$, we find sequences $\left\{c_{t}, l_{t}(\varepsilon), b_{t+1}(\varepsilon)\right\}_{t=1}^{T}$ for every type $\left\{\varepsilon_{1}, a_{1}\right\} \in \Upsilon \times A$. Using the equilibrium steady state distribution $\mu$ under incomplete markets, we aggregate these choices and obtain a sequence of aggregate quantities $\left\{K_{t}, L_{t}\right\}_{t=1}^{T}$. From the sequence of production factors we can use the firm optimality conditions to obtain a new sequence of prices $\left\{\hat{r}_{t}^{0}, \hat{w}_{t}^{0}\right\}_{t=1}^{T}$. If $\left\{\hat{r}_{t}^{0}, \hat{w}_{t}^{0}\right\}_{t=1}^{T}=\left\{r_{t}^{0}, w_{t}^{0}\right\}_{t=1}^{T}$ we have found the sequence of equilibrium prices, if not we have to try with a new sequence $\left\{r_{t}^{1}, w_{t}^{1}\right\}_{t=1}^{T}$.

In the paper I have used $T=200$ and I have solved the fixed point problem by successive approximations: given an initial guess $\left\{r_{t}^{0}, w_{t}^{0}\right\}_{t=1}^{T}$ I obtain a new sequence $\left\{\hat{r}_{t}^{0}, \hat{w}_{t}^{0}\right\}_{t=1}^{T}$. Then, I have updated the iteration as follows:

$$
\left\{r_{t}^{1}, w_{t}^{1}\right\}_{t=1}^{T}=\chi\left\{\hat{r}_{t}^{0}, \hat{w}_{t}^{0}\right\}_{t=1}^{T}+(1-\chi)\left\{r_{t}^{0}, w_{t}^{0}\right\}_{t=1}^{T}
$$

with $\chi=0.05$. Obviously, this small updating factor generates a very slow convergence process but it has been needed to avoid a diverging process. 